\title{
Spectrum of Neonatal Sepsis in NICU
}

\author{
Dr. Amar Verma, Dr. Binita Nancy Khalkho, Dr. Anita Verma, \\ Dr. Manika Verma, Dr. Ravikant Narayan \\ Department of Paediatrics and Neonatology, Rajendra Institute Of Medical Sciences, Ranchi-834-009
}

\begin{abstract}
Neonatal sepsis is one of the commonest conditions encountered in neonatal nursery of any institution. Dynamicity of changing bacterial flora and frequent emergence of resistant strain is main problem. It requires appropriate and accurate clinical \& laboratory diagnosis.

Present study was aimed to find out spectrum of neonatal sepsis causing microorganism in our set up and comparing same from our previous study done in 2007-08.

During study period 106 cases of diagnosed newborns were included. Out of this 43 newborn were culture positive. Current study shows predominance of gram positive staphylococcus (8.5\%) followed byklebsiella, whereas previous study had shown predominance of gram negative klebsiella (33.3\%).
\end{abstract}

Keywords: Septicaemia, Culture isolate, Risk factors.

\section{Introduction}

Bacterial sepsis is major cause of neonatal morbidity and mortality. A large no. of bacterial and non bacterial organism causes sepsis during intrauterine, perinatal period or postpartum period. Neonatal bacterial sepsis is characterized by positive blood culture, Raised acute phase reactants with clinical symptoms or signs such as lethargy, respiratory distress, poor feeding or vomiting, abdominal distension, seizures and shock characterized by prolonged capillary refill time. Multiorgan failure and severe shock may be manifestations of severe sepsis.

Neonatal sepsis may be classified as early onset sepsis (EOS), Late onset Sepsis (LOS) or very late onset Sepsis (VLOS). Sepsis presenting within 72 hrs. of life are called Early onset sepsis whereas manifestations after $72 \mathrm{hrs}$. are called Late onset sepsis. Some authors use term as very late onset sepsis in conditions manifesting after 30 days of age. In very late onset sepsis, Infection usually comes from community or is acquired during NICU stay but symptoms appear after discharge. This special classification helps in suspecting organism, planning investigation, choosing antimicrobial agents, prognostication and follow up. Neonatal infections are estimated to cause about 1.6 million deaths worldwide and $40 \%$ of all neonatal deaths due to sepsis occur in developing countries ${ }^{1}$.

According to the data from National Neonatal Perinatal Database (NNPD, 2002-03) the incidence of neonatal sepsis is 30 per 1000 live births and sepsis to be one of the commonest causes of neonatal mortality contributing to $19 \%$ of all neonatal deaths.

The bacteriological profile of neonatal sepsis is constantly under change, more so with advances in early diagnosis, treatment and increased survival of preterm babies. Sepsis, if identified and treated appropriately in time, has very good outcome thus the bacteriological profile needs to be reviewed from time to time.

This study was conducted to know the current incidence of sepsis among the babies admitted in our hospital, the pattern of etiological agent in neonatal sepsis and the antibiotic sensitivity profile of the microorganisms isolated.

\section{Objective}

To study the spectrum of neonatal sepsis in 2014-15 and comparison of similar type of study done in 2007-2008 in RIMS, Ranchi

\section{Setting}

This study was conducted in the neonatal intensive care unit in the department of paediatrics in Rajendra Institute of Medical Sciences, Ranchi from May 2014 to April 2015.

\section{Materials And Methods}

This observational, prospective, single centre study consists of 106 cases diagnosed as clinical sepsis from May 2014 to April 2015 at level III NICU of Rajendra Institute of Medical sciences. The study was carried out on clinically suspected and already admitted cases in NICU. 
Blood sample for blood culture and sensitivity and sepsis screen (excluding mESR) and other relevant investigations were sent $\mathrm{t}$ our pathology and Microbiology department.. $\mathrm{X}$ ray, CSF study and cultures of urine etc were done only in selected cases.

Blood cultures were sent for bacterial as well as fungal organisms by standard method. Blood cultures were plated in Mac-Conkey and blood agar. For fungal culture, bottles were cultured using sabouraud's agar and incubated at $25 \mathrm{deg} \mathrm{C}$ and $37 \mathrm{deg}$ c. Sub cultures were made at $24 \mathrm{hrs}, 48 \mathrm{hrs}$, and $72 \mathrm{hrs}$ and on 7 th day. The plates were observed for evidence of growth, the colony morphology was noted, a smear was made and gram stained. If gram stain show yeast cell, the isolate was further processed for species identification.

\section{Observation}

106 cases diagnosed as clinical sepsis from May 2014 to April 2015 were selected for study.

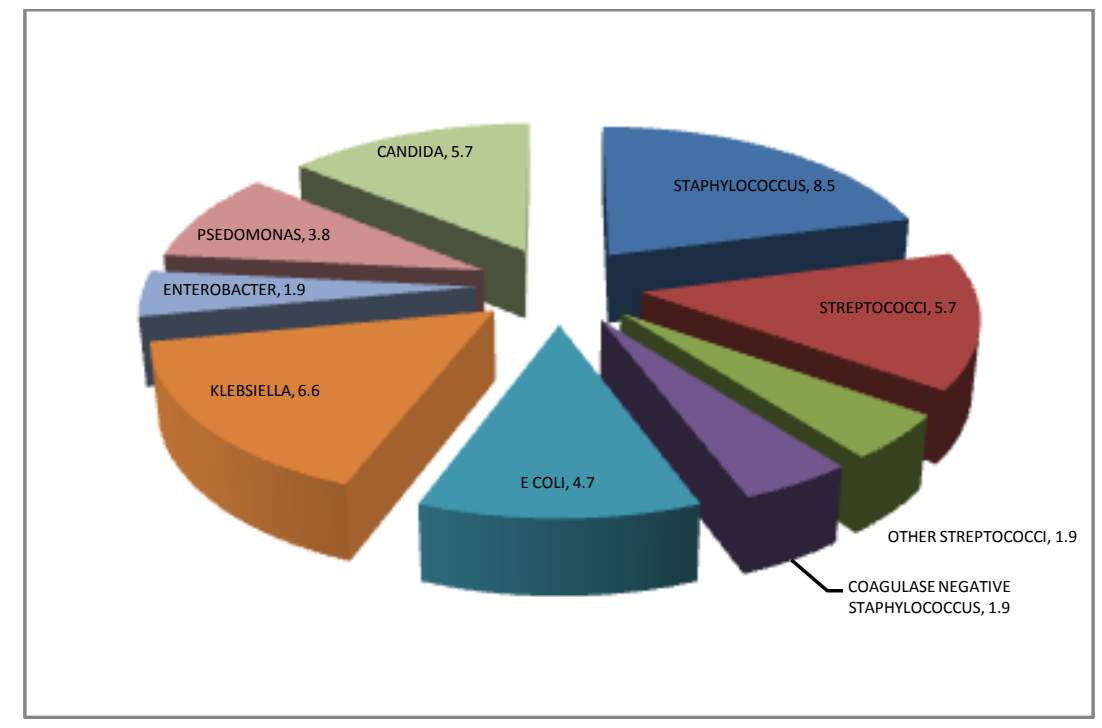

\begin{tabular}{|c|c|c|c|c|}
\hline Gram Positive & {$[\mathrm{n}]$} & $\begin{array}{c}\text { Gram } \\
\text { negative }\end{array}$ & {$[\mathrm{n}]$} & Fungal culture \\
\hline Staphylococcus & 9 & Klebsiella & 7 & $\begin{array}{c}\text { Candida spp } \\
{[\mathrm{n}=6]}\end{array}$ \\
\hline GB Streptococcus & 6 & E. Coli & 5 & \\
\hline $\begin{array}{c}\text { Coagulase negative } \\
\text { staphylococcus }\end{array}$ & 2 & Pseudomonas & 4 & \\
\hline Other streptococcus & 2 & Enterobacter & 2 & \\
\hline Total & 19 & & 18 & 6 \\
\hline
\end{tabular}

IV. Discussion

Verma et al (2007-08) had also conducted profile of neonatal sepsis in RIMS, Ranchi, shown in following table-

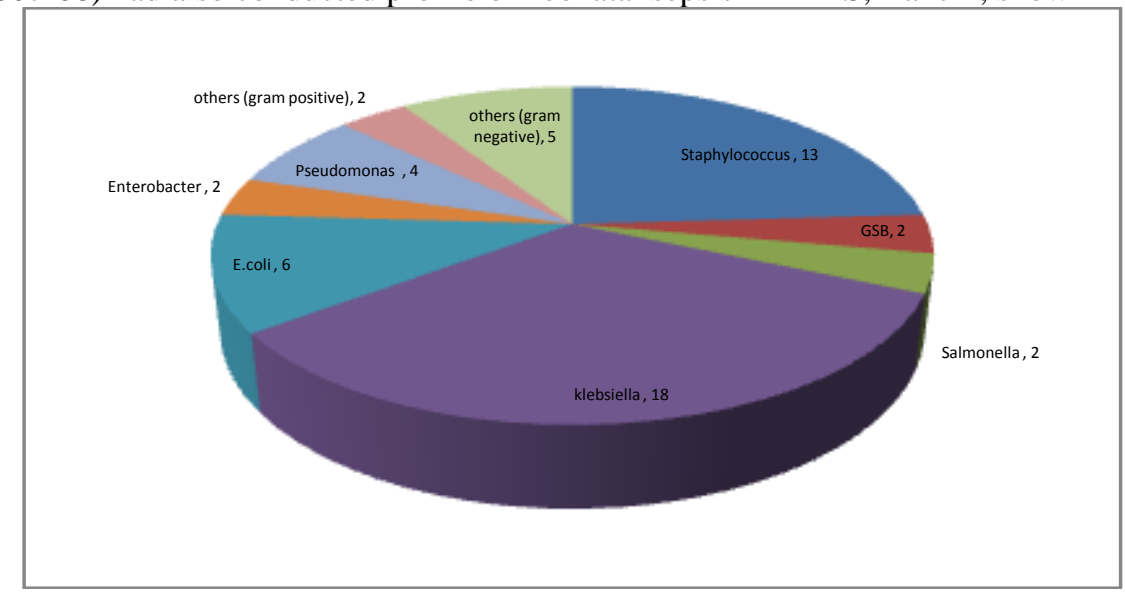




\begin{tabular}{|c|c|c|c|}
\hline Gram positive & {$[\mathrm{n}]$} & Gram Negative & {$[\mathrm{n}]$} \\
\hline Staphylococcus & 13 & Klebsiella & 18 \\
\hline GBS & 2 & E. coli & 6 \\
\hline Salmonella & 2 & Pseudomonas & 4 \\
\hline Other gram positive & 2 & Enterobacter & 2 \\
\hline & & $\begin{array}{c}\text { Other gram } \\
\text { negative }\end{array}$ & 5 \\
\hline
\end{tabular}

\begin{tabular}{|l|l|l|}
\hline & Present Study (2015) & Previous study (2007-08)106 \\
\hline Total no of patients & 106 & 187 \\
\hline $\begin{array}{l}\text { Sex- Male } \\
\text {-Female }\end{array}$ & 52 & - \\
\hline $\begin{array}{l}\text { Age } \\
\text {-Early Onset Sepsis } \\
\text {-Late Onset Sepsis }\end{array}$ & 54 & - \\
\hline & 32 & \\
\hline Name of organism & 74 & \\
\hline Gram positive= & Present study & $\begin{array}{l}\text { Previous study (2007-08) } \\
\text { Number of cases and percent }\end{array}$ \\
\hline Staphylococcus aureaus & Number of cases and percent & \\
\hline Other streptococcus & $9(8.5 \%)$ & $13(24.07 \%)$ \\
\hline Coagulase negative Staphylococcus & $6(5.7 \%)$ & $2(3.7 \%)$ \\
\hline Salmonella & $2(1.9 \%)$ & - \\
\hline Others & $2(1.9 \%)$ & - \\
\hline Gram negative $=$ & - & $2(3.7 \%)$ \\
Klebsiella & - & $2(3.7 \%)$ \\
\hline E coli & $7(6.6 \%)$ & $18(33.33 \%)$ \\
\hline Enterobacter & $5(4.7 \%)$ & $6(11.11 \%)$ \\
\hline Pseudomonas & $2(1.9 \%)$ & $2(3.7 \%)$ \\
\hline Others & $4(3.8 \%)$ & $4(7.41 \%)$ \\
\hline Candida & - & $5(9.25 \%)$ \\
\hline & $6(5.7 \%)$ & - \\
\hline
\end{tabular}

The present study has demonstrated change from the previous result obtained in 2007-08. The present study shows a predominance of gram positive staphylococcus, Whereas previous study had shown predominance of gram negative Klebsiella. The present study also shows a good amount of Candida sp. in the blood culture of the neonates. A rising trend has been noted in the incidence may be due to availability of newer diagnostic tools. Preterm infants are predisposed to Candida infections because of immaturity of their immune system, frequent invasive interventions and prolonged hospital stay. It may not be a coincidental finding $\&$ needs further study.

Risk factors for hospital acquired infections include lower gestational age, low birth weight, invasive procedures, invasive devices (intravenous catheters, endotracheal tubes, parenteral nutrition and intravenous lipids), colonisation of skin, gastrointestinal tract and airway with invasive organism, nursery overcrowding and hand washing All these factors may lead to a rise in hospital acquired infections. The preponderance of gram positive organisms may be due to above mentioned conditions.

\section{Conclusion}

The bacteriological profile has changed in the past few years in our institution thus it is important that it should be reviewed from time to time to set up empirical management protocol. The antibiotic sensitivity profile also needs to be reviewed. This may help in use of appropriate antibiotics for proper duration thus leading to reduction in misuse of antibiotics.

\section{Bibliography}

[1]. National Neonatology Forum India Evidence Based Clinical Practice Guidelines, Oct 2010, Management of Neonatal sepsis; pg 156

[2]. For the Million Death Study Collaborators. Causes of neonatal and child mortality in India: nationally representative mortality survey. Lancet. 2010;376(9755):1853-1860. doi:10.1016/S0140-6736(10)61461-4.

[3]. NNPD network. National Neonatal Perinatal Database- report for the year 2002-2003. NNF NNPD network. 2005. New Delhi. Ref Type: Report.

[4]. Tsering DC, Chanchal L, Pal R, Kar S. Bacteriological Profile of Septicemia and the Risk Factors in Neonates and Infants in Sikkim. Journal of Global Infectious Diseases. 2011;3(1):42-45. doi:10.4103/0974-777X.77295.

[5]. Chandra Madhur Sharma, Ravi Prakash Agrawal, Hariom Sharan, Bijay Kumar, Deepti Sharma, Santokh Singh Bhatia J Clin Diagn $\begin{array}{lllll}\text { Res. } 2013 \quad \text { November; 7(11): } & \text { 2511-2513. Published online } & \end{array}$ 30. doi: 10.7860/JCDR/2013/6796.3594PMCID: PMC3879858.

[6]. Monjur F(1), Rizwan F, Asaduzzaman M, Nasrin N, Ghosh NK, Apu AS, Haque F. Antibiotic sensitivity pattern of causative organisms of neonatal septicemia in an urban hospital of Bangladesh. Indian J Med Sci. 2010 Jun;64(6):265-71. doi: 10.4103/00195359.99605

[7]. Ramesh A, Ashok Deorari, Vinod K Paul,AIIMS protocol in Neonatology,Neonatal sepsis; pg 163

[8]. John P Cloharty, Eric C Eicheenwald, Ann R Stark.Manual of neonatal care. 6thed.New Delhi: Wolters klauwer Pvt.Ltd;2010.p.274. 
[9]. Patricia Ferrieri and Linda D.Wallen. Neonatal Bacterial sepsis.Avery s diseases of newborn. $9^{\text {th }} 2012$ ed. p.538

[10]. Corrigan: Thrombocytopenia. A lab sign of septicaemia in infants and children": Journal of pediatrics: 1974; 85-219.

[11]. Philip AG, Hewitt JR. Early diagnosis of neonatal sepsis. Pediatrics 1980; 65:1036-41.

[12]. Sundaram V, Kumar P, Narang A. Bacterial profile of early versus late onset neonatal sepsis in a North Indian tertiary care centre: Heading towards a change. J Pediatr Infect Dis 2009; 4: 241-245

[13]. Paul VK, Agarwal R. Neonatal sepsis. In: Mondkar J, Pejavar RK, editors. NNF Manual of Neonatal Care. Bangalore: Prism Publishers; 2004. p. 121-34.

[14]. Patricia Ferrieri and Linda D.Wallen. Neonatal Bacterial sepsis.Avery s diseases of newborn. $9^{\text {th }} 2012$ ed. p.562.

[15]. Aftab R, Iqbal I. Bacteriological agents of neonatal sepsis in NICU at Nishtar hospital, Multan. J Coll Physicians Surg Pak. 2006 Mar;16(3):216-9. [PubMed] 